\title{
Abstracts of articles
}

\section{Lionel Frost}

Coping in their own way: Asian cities and the problem of fires

The debate about the ability of Third World cities today and in the future to cope with rapid population growth has taken place with virtually no reference to urban history. This article seeks to remedy that, examining how three of Asia's largest cities during the pre-modern period coped with the problem of major fires. It examines the nature of the problem, its causes and its economic significance. The article concludes by considering the implications of this history for the current debate.

\section{Geoffrey Clark}

\section{Life insurance in the society and culture of London, 1700-75}

This article examines the rise of co-operative life insurance societies and the market for life insurance in the early eighteenth century. Life insurance offered the middling sort in particular an opportunity to associate together for mutual economic protection and also provided them with a means to advance a set of reforming ideals. Until 1774, however, the lack of any legal restrictions on who might insure whom meant that prudential insuring existed alongside gambling on other people's lives, leading to a clash of property interests among the societies' members. Ultimately, a new moral technology was developed that segregated licit from illicit motives for insuring and also curtailed the proprietary rights insurance society members had previously exercised over their own policies, subjecting them instead to an impersonal financial bureaucracy.

\section{Bill Luckin and Graham Mooney}

Urban history and historical epidemiology: the case of London, 1860-1920

Advocating a closer relationship between urban and epidemiological history, the paper concentrates, firstly, on a critical overview of the McKeown thesis. It next identifies components from the work of John 
Landers as a means of constructing a structural model of mortality experienced during the period under review. The paper goes on to examine the manner in which this model might be applied to London during an era in which the classic killing infections of the mid-nineteenth century were gradually replaced by non-infectious causes of death. Returning, by way of conclusion, to the theme of an integration of urban and epidemiological methodologies, attention is drawn to the explanatory potential of a fully historical economy of health and disease.

\section{John Welshman}

Eugenics and public health in Britain, 1900-40: scenes from provincial life

Historians have attempted to assess the impact of eugenics on public health provision in a number of fields including mental health, birth control, voluntary sterilization and housing. However, most of this work has concentrated on debates at the national level, and we know much less about the ways in which eugenics may have helped shape health services in provincial cities. It has been suggested that Leicester was a city in which eugenicists were particularly prominent, and this article examines the impact of eugenics on three aspects of public health between 1900 and 1940; mental health, birth control and housing. It concludes that while eugenics did have a practical outcome in mental health and birth control, its influence on housing policy was more elusive, and 1935 marked a turning-point after which eugenics was less significant in health policy and intellectual life. 